ICES Abstract, 300 words or less

Session Code ICES408 (Regenerable Life Support Processes and Systems)

Authors: Amy Lin, Frederick Smith, Jeffrey Sweterlitsch, Tim Nalette, William Papale

\title{
Further Testing of an Amine-Based Pressure-Swing System for Carbon Dioxide and Humidity Control
}

\begin{abstract}
In a crewed spacecraft environment, atmospheric carbon dioxide $\left(\mathrm{CO}_{2}\right)$ and moisture control are crucial. Hamilton Sundstrand has developed a stable and efficient amine-based $\mathrm{CO}_{2}$ and water vapor sorbent, SA9T, that is well suited for use in a spacecraft environment. The sorbent is efficiently packaged in pressure-swing regenerable beds that are thermally linked to improve removal efficiency and minimize vehicle thermal loads. Flows are all controlled with a single spool valve. This technology has been baselined for the new Orion spacecraft. However, more data was needed on the operational characteristics of the package in a simulated spacecraft environment. A unit was therefore tested with simulated metabolic loads in a closed chamber at Johnson Space Center during the last third of 2006. Those test results were reported in a 2007 ICES paper. A second test article was incorporated for a third phase of testing, and that test article was modified to allow pressurized gas purge regeneration on the launch pad in addition to the standard vacuum regeneration in space. Metabolic rates and chamber volumes were also adjusted to reflect current programmatic standards. The third phase of tests was performed during the spring and summer of 2007. Tests were run with a range of operating conditions, varying: cycle time, vacuum pressure (or purge gas flow rate), air flow rate, and crew activity levels. Results of this testing are presented and potential flight operational strategies discussed.
\end{abstract}




\section{Further Testing of an Amine-Based Pressure-Swing System for Carbon Dioxide and Humidity Control}

\begin{abstract}
In a crewed spacecraft environment, atmospheric carbon dioxide $\left(\mathrm{CO}_{2}\right)$ and moisture control are crucial. Hamilton Sundstrand has developed a stable and efficient amine-based $\mathrm{CO}_{2}$ and water vapor sorbent, SA9T, that is well suited for use in a spacecraft environment. The sorbent is efficiently packaged in pressure-swing regenerable beds that are thermally linked to improve removal efficiency and minimize vehicle thermal loads. Flows are controlled with a single spool valve. This technology has been baselined for the new Orion spacecraft, but more data was needed on the operational characteristics of the package in a simulated spacecraft environment. A unit was tested with simulated metabolic loads in a closed chamber at Johnson Space Center during the last third of 2006. Those test results were reported in a 2007 ICES paper. A second test article, modified to allow pressurized gas purge regeneration on the launch pad in addition to the standard vacuum regeneration in space, was incorporated for further testing in 2007. Metabolic rates and chamber volumes were also adjusted to reflect current program standards. Tests were run with a range of operating conditions, varying: cycle time, vacuum pressure (or purge gas flow rate), air flow rate, and crew activity levels. Results of this additional testing are presented and potential flight operational strategies discussed.
\end{abstract}

\section{INTRODUCTION}

Human beings produce carbon dioxide $\left(\mathrm{CO}_{2}\right)$ when they breathe, but too high a concentration in the atmosphere around them can quickly become toxic. For this reason, $\mathrm{CO}_{2}$ control is critical in the closed environment of a spacecraft. Humans also breathe out water vapor and
Amy Lin

Jacobs Technology

Frederick Smith and Jeffrey Sweterlitsch

NASA Johnson Space Center

Tim A. Nalette and William Papale Hamilton Sundstrand Space Systems Int'I. exchange water vapor with the atmosphere through their skin. Although excessive water $\left(\mathrm{H}_{2} \mathrm{O}\right)$ vapor is not dangerous to humans, it can be uncomfortable, and it can be hazardous to the electronic equipment in a spacecraft cabin, particularly if it condenses in undesired locations.

In the past, spacecraft have typically used separate systems to control $\mathrm{CO}_{2}$ and humidity. Common $\mathrm{CO}_{2}$ control methods have included sorption by lithium hydroxide or zeolite compounds, and water has typically been collected by condensing heat exchangers. However, those chemical sorption systems have tended to be large and heavy, whether regenerable or not, and condensate water collection systems require significant support by a lower temperature thermal control system.

As an alternative to traditional $\mathrm{CO}_{2}$ sorption systems, Hamilton Sundstrand has spent many years developing amine-based vacuum-regenerated adsorption systems. The first major implementation of this type of system, known as the Regenerative $\mathrm{CO}_{2}$ Removal System (RCRS), was tested on the Space Shuttle in the early 1990s. This design and the associated amine have gone through a number of improvement cycles in the intervening years. The current iteration of the system uses a pair of interleaved-layer beds filled with SA9T, which is a sorbent system comprised of plastic beads coated in an immobilized liquid amine, to remove $\mathrm{CO}_{2}$ and water vapor from a spacecraft cabin atmosphere.

SA9T, in addition to being a good $\mathrm{CO}_{2}$ sorbent, also has a great affinity for water vapor. When water vapor is removed from the cabin atmosphere with a regenerable sorbent instead of a traditional condensing heat exchanger, the spacecraft cooling system can be greatly simplified by eliminating a fairly significant heat load as 
well as the need for a low-temperature cooling loop. Hamilton Sundstrand studies have shown the amine to be very stable over long periods and the interleaved bed system minimizes total cabin heat loads due to the adsorption and desorption processes. For these and other reasons, this technology has been baselined as the primary $\mathrm{CO}_{2}$ and water vapor removal device for the new Orion spacecraft.

While Hamilton Sundstrand's technology was already relatively well developed and had undergone subscale and open-loop testing, NASA's Exploration Life Support (ELS) and Orion development groups wanted more details on the performance of the device in a realistic spacecraft environment. The ELS Air Revitalization Systems team at Johnson Space Center (JSC) refitted an existing test chamber, called the Air Revitalization Technology Integration Chamber (ARTIC), to test Hamilton Sundstrand's technology, which the Air Revitalization team calls the $\mathrm{CO}_{2}$ And Moisture Removal Amine Swing-bed, or CAMRAS.

The JSC team tested a single CAMRAS unit in two test phases between August and December of 2006 . The preliminary results of those tests were presented in ICES paper 2007-01-3156 ${ }^{1}$. A second CAMRAS unit of modified design was added to the system for the third phase of testing in two parts: the first in late April/early May, and the second from late July through late August of 2007. Final results of the third phase of testing are presented here, along with some updated data from the first two phases that provides context for the Phase 3 data. Also included are key lessons learned and recommendations for physical and operational implementation of the CAMRAS in the Orion vehicle.

Note to reviewers: all units in the paper will be converted to metric for the final version. Similarly, all plots will be reworked in the final version for units, legibility, and to conform to ICES paper standards. US Customary units and pre-existing plots were inserted as placeholders for expedience in getting this draft out.

\section{TEST RIG DESCRIPTION}

Figure 1 shows a functional overview of the Phase 3 modified test rig used to test the CAMRASes at JSC. It is briefly described in the following subsections. A photo of the test articles inside the chamber for Part 1 of the Phase 3 testing is presented in Figure 2, and for Part 2 in Figure 3.

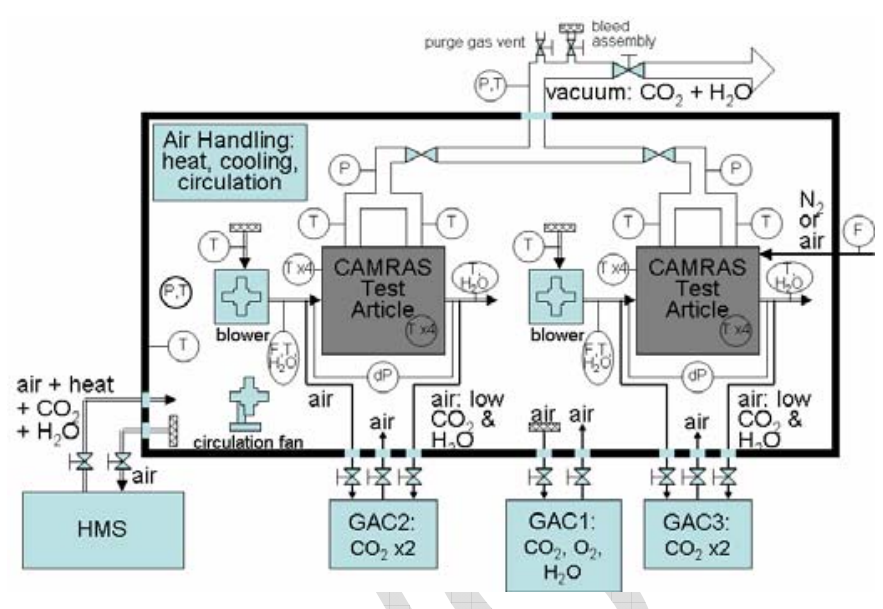

Figure 1 - CAMRAS Test Rig Functional Overview

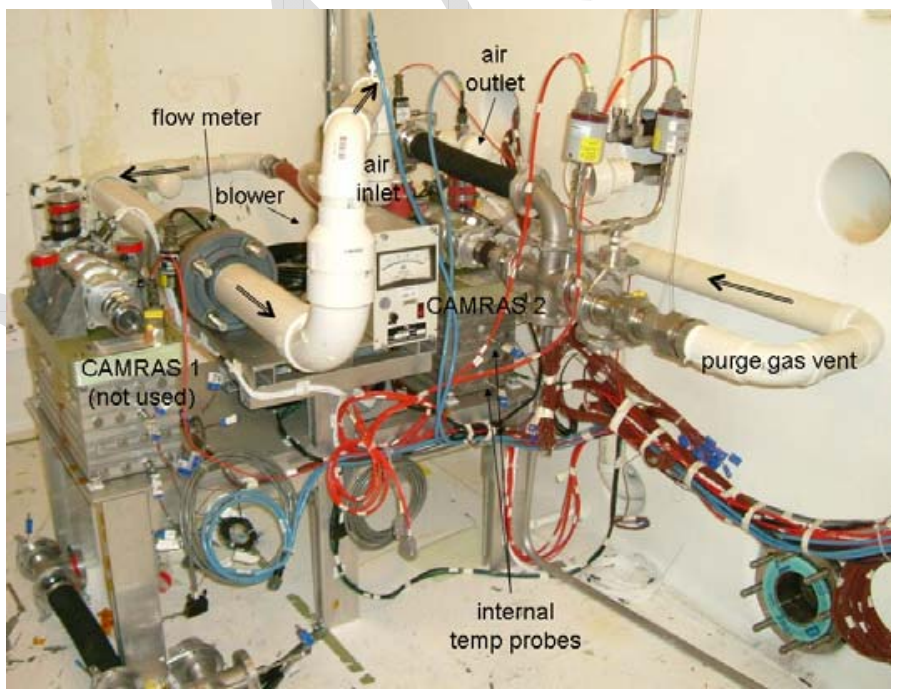

Figure 2 - Phase 3 Part 1 CAMRAS Test Article Inside Test Chamber

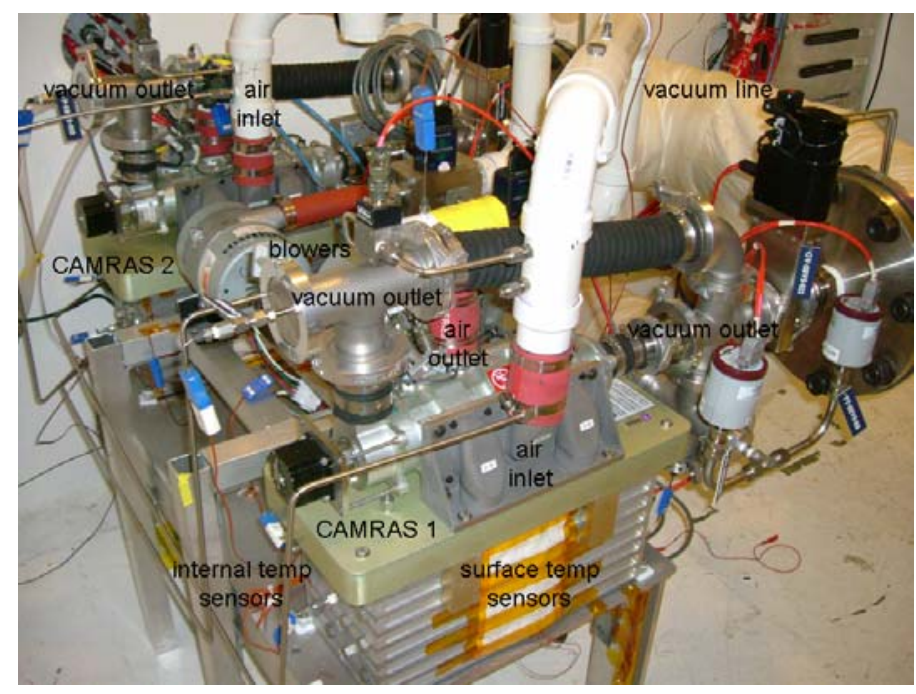

Figure 3 - Phase 3 Part 2 CAMRAS Test Articles Inside Test Chamber 
TEST ARTICLE - The CAMRAS technology uses a pair of interleaved multilayer beds filled with sorbent beads. In each CAMRAS, a spool-type valve directs airflow from the cabin, through the adsorbing bed, and back to the cabin while isolating the desorbing bed to a direct line to space vacuum. The valve periodically switches position, swapping the bed functions and equalizing pressure between the beds as it travels, which helps minimize ullage air loss. Each adsorption or desorption period is called a half-cycle.

Figure 4 shows a simple schematic of the CAMRAS operation. This original design pulls a vacuum on both ends of the desorbing bed, and that design is called "dual-end desorb". The test article used in Phase 1 and 2 tests was a dual-end desorption unit. When it became one of two test articles, it became known as CAMRAS 1 (abbreviated as $\mathrm{C} 1$ in several tables).

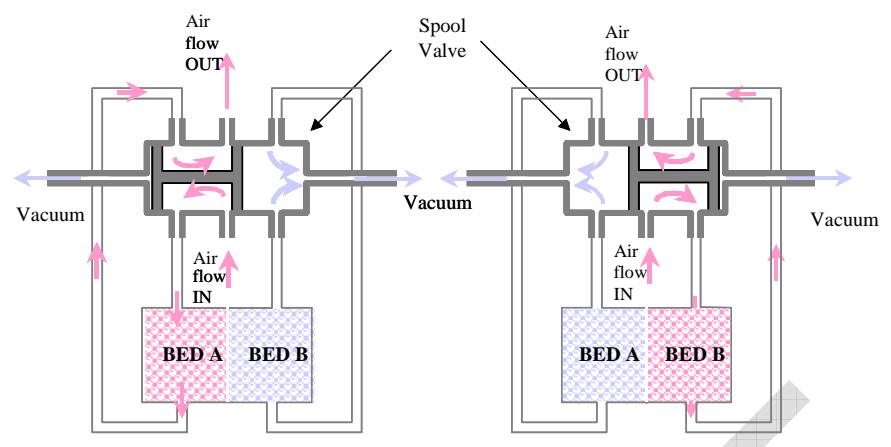

Figure 4 - CAMRAS Process Flow

A good vacuum source would be very difficult to implement on the launch pad, and the CAMRAS cannot provide $\mathrm{CO}_{2}$ removal for any significant length of time without a desorption mechanism. Rather than implement an additional $\mathrm{CO}_{2}$ removal system specifically for use on the launch pad, Hamilton Sundstrand instead modified the CAMRAS manifold so that dry pressurized gas from a launch pad source can be used to purge the accumulated $\mathrm{H}_{2} \mathrm{O}$ and $\mathrm{CO}_{2}$ out of the desorbing beds. Due to this alternate functionality, however, the vacuum desorption is consequently restricted to pulling on a single end of the desorbing bed ("single-end desorb"). In Phase 3 Part 1, a single-end desorb unit was tested with purge gas only (no vacuum). This test article is named CAMRAS 2 in this paper (abbreviated: C2).

The highly porous beads in this device are coated with a liquid amine, which becomes immobilized in the pellet pores. This sorbent system, known as SA9T, adsorbs both carbon dioxide and water vapor. The adsorption reaction is exothermic and the vacuum-desorption reaction is endothermic; the interleaving of bed layers helps conserve the overall system thermal energy and no direct heating or cooling of the device is required.

In the projected Orion application of this technology, three separate CAMRAS assemblies will be installed in the vehicle. Two will operate in parallel for a crew of four to six people, and the third will be reserved as a spare. The beds are sized such that, in an emergency, a single CAMRAS could maintain the cabin $\mathrm{CO}_{2}$ at safe levels for a crew of six indefinitely.

TEST CHAMBER - The ARTIC test chamber is a closed and sealed environment directly monitored for temperature and pressure. The chamber air conditions were also analyzed by an external sampling rack (Gas Analyzer Console 1, or GAC1) for dew point and for $\mathrm{CO}_{2}$ and $\mathrm{O}_{2}$ concentrations. The volume of the chamber was somewhat larger than the volume of the Orion capsule. The total free volume was therefore reduced to approximately $16.2 \mathrm{~m}^{3}$ by a sealed aluminum sheet wall constructed inside the chamber. The chamber leak rate was determined by a $\mathrm{CO}_{2}$ decay test with the external air loop systems active and running. Total leakage rates were determined to be $1.4 \%$ per day before the beginning of the Phase 3 testing. Inside the chamber is a condensing heat exchanger with blower, which was run with the coolant loop above condensing temperatures in all of the CAMRAS tests to control temperature and provide ambient circulation. An additional free-standing fan was used to improve the ambient circulation. For a few test scenarios that used only one of the two test articles, the chamber volume was further reduced to about $8.0 \mathrm{~m}^{3}$, or half the projected vehicle free volume, with airtight space-filling boxes because a single CAMRAS was designed to do half the work nominally needed in the Orion.

METABOLIC SIMULATION - A Human Metabolic Simulator (HMS) was used with the chamber for this testing. It is designed to simulate human production of heat, $\mathrm{CO}_{2}$, and exhaled $\mathrm{H}_{2} \mathrm{O}$ vapor. The heat production function is considered extraneous to CAMRAS testing, but incidental heat is added to the atmosphere as part of the steam generation process used to represent metabolic water production. Liquid water is pumped into a hot oil/water heat exchanger at a metered rate, the resulting steam is allowed to achieve slight pressurization (up to about $69 \mathrm{kPa}$ gauge), and the steam is then injected directly into the HMS air circulation stream. $\mathrm{CO}_{2}$ is separately injected into the HMS air stream from a pressurized and flow-controlled gas source.

The HMS can simulate at least eight people at once, although the Phase 3 CAMRAS tests were typically run with simulated loads of four or six people. Exercise scenarios were run with only four simulated people, as a crew of six would not have enough space to exercise in the Orion capsule. Table 1 lists the metabolic constituent generation rates used in this CAMRAS testing, which are simply halved when metabolic loads of two or three people are tested with a single test article. These rates are based on the early 2007 version of NASA's Human-Systems Integration Requirements ${ }^{3}$ (HSIR) and represent 82-kg males. These metabolic 
rates for sleep and nominal activity levels were updated from those used in Phase 1 and 2 testing. The $\mathrm{CO}_{2}$ rates decreased slightly from the earlier testing, and the water rates increased somewhat more.

\begin{tabular}{|c|c|c|c|c|c|}
\hline $\begin{array}{l}\text { Crew Size } \\
\text { \& Activity }\end{array}$ & $\begin{array}{l}\frac{0}{d 0} \\
\frac{d}{N} \\
\forall\end{array}$ & 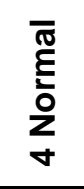 & 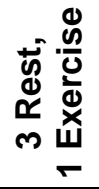 & $\begin{array}{l}\frac{0}{d} \\
\frac{d}{5} \\
0\end{array}$ & $\begin{array}{l}\sum_{0}^{\bar{\Xi}} \\
\sum_{0}^{0}\end{array}$ \\
\hline $\begin{array}{l}\text { Metabolic } \\
\mathrm{CO}_{2} \\
\text { Generation } \\
\text { Rate (g/min) }\end{array}$ & 1.82 & 2.88 & $\begin{array}{l}\text { peak } \\
7.15\end{array}$ & 2.73 & 4.32 \\
\hline $\begin{array}{l}\text { Metabolic } \\
\mathrm{H}_{2} \mathrm{O} \\
\text { Generation } \\
\text { Rate (g/min) }\end{array}$ & 2.52 & 4.71 & $\begin{array}{l}\text { peak } \\
21.38\end{array}$ & 3.78 & 7.06 \\
\hline
\end{tabular}

Table 1 - Human-Systems Integration Requirements Metabolic Constituent Generation Rates Used in Phase 3 CAMRAS Testing

TEST ARTICLE AIR SIDE - The CAMRASes were each outfitted with a variable-speed blower with flow meter, a differential pressure sensor between the canister inlet and outlet, and temperature sensors at various locations in the air path, including four on the external surface of the canister and four more probes inside the amine beds. Samples from the inlet and outlet lines were pulled through an external sampling rack (GAC3), where $\mathrm{CO}_{2}$ concentration was measured. GAC3 was a new sampling rack developed explicitly for the CAMRAS testing based on lessons learned about sample rack plumbing in Phases 1 and 2. Thin-film aluminum oxide moisture sensor probes in the inlet and outlet lines provided data on the moisture levels in the process air stream.

Blower performance and pressure drop across the CAMRASes was tested before Phase 1, Phase 3 Part 1 , and Phase 3 Part 2. Figure 5 shows all of the pressure drop test results. In this plot, dashed lines represent Bed A and solid lines Bed B. CAMRAS 1 pressure drop was higher than CAMRAS 2 in all flow tests, possibly because the first unit's spool valve internal parts were not finished as smoothly as the second unit's. Slight manifold air flow path differences between dual and single-end desorb units may also figure into this. Bed A's pressure drop was higher than Bed B's in all tests for both CAMRAS units, which is most likely due to differences in the internal air flow path for the two beds, which are physically different due to the layered structure of the units.

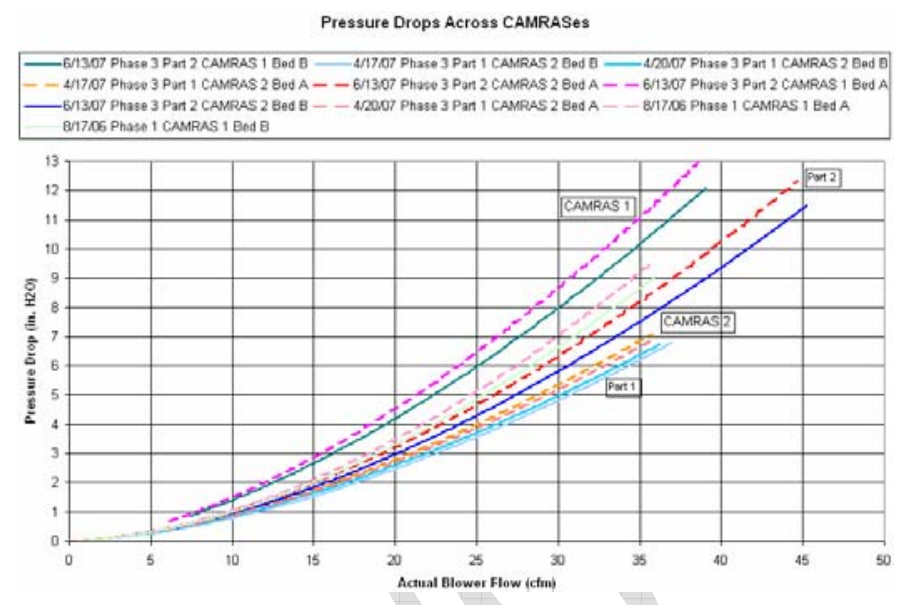

Figure 5 - CAMRAS Pressure Drop Comparison

The lower set of lines for CAMRAS 1 were the results from the Phase 1 checkouts. The blower and flow meter from that test rig were reused for CAMRAS 2 for the Phase 3 Part 1 test, but the plumbing had been modified slightly and the different test articles have different innate pressure drops. Due to flow range issues, the blower controls calibration was changed a couple of days later and retested. These two tests form the lower set of CAMRAS 2 lines. For Phase 3 Part 2, the blowers, flow meters, and inlet plumbing on both CAMRAS units were changed, so the pressure drop was checked yet again. The inlet air plumbing was much shorter than in prior tests simply due to the use of a new flow meter that did not require the flow straighteners upstream and downstream of it. This most likely caused the actual air flow rate going into the CAMRASes to be slightly higher than in the earlier tests, which would explain the higher pressure drop at any given sensed flow rate.

TEST ARTICLE VACUUM SIDE - Because the CAMRAS is designed to desorb the adsorbed gases to space, a vacuum source was required for this testing. Based on the lessons learned in the Phase 1 and 2 testing, a new dedicated vacuum pump system was implemented for Phase 3 Part 2 testing. A pair of Roots blowers were installed in series upstream of a dry screw vacuum pump and connected to the test article via large vacuum lines. Pressures of as little as $7 \mathrm{~Pa}$ were achieved at the test article when the test article was idle. This is called the base pressure. When a CAMRAS operates, there is a brief pulse of gas dumped into the vacuum system every time the spool valve changes position, and the pressure then falls off exponentially. The relatively steady pressure toward the end of each half-cycle is called the cycling pressure. It was easily maintained below $25 \mathrm{~Pa}$ during most of the test cases.

\section{TEST CASES}

The testing presented here was the third phase in a continuing series of CAMRAS tests at JSC. Phase 1 
testing established baseline performance data in a few nominal operations situations and touched on other operational scenarios. Phase 2 was dedicated primarily to better refining the performance of the CAMRAS with a range of air flow rates and pressure-swing cycle times, but also investigated an extended three-day scenario including a realistic profile of normal, sleep, and exercise metabolic loads.

Phase 3 Part 1 testing investigated the performance of a modified CAMRAS unit when regenerated with a pressurized gas stream instead of vacuum. Spool valve cycle times and desorption purge gas flow rates were varied in a matrix of test conditions.

Part 2 of Phase 3 compared the performance of the original and modified CAMRAS units, and examined the performance of the units with various metabolic rates at a number of additional flow air flow rates and pressureswing cycle times. The baseline cases of Phase 1 were repeated on both units working together, with the revised nominal, sleep, and exercise metabolic rates. The nominal metabolic load test was also performed on the two individual units to provide a transitionary comparison point between old individual unit tests and new combined tests. Further matrix testing was performed to build on the results obtained in Phase 2: a few more nominal metabolic load cases at a previously-untested air flow rate were added, a few exercise cases were examined, and a number of sleep cases were performed. One case at each metabolic load level was run with air flow rates and cycle times explicitly requested by computer modeling analysts to help validate their model results. Two reduced vacuum cases like those run in Phase 1 were completed in Phase 3 Part 2, as were two simulated failure cases with 6 crew members on a single CAMRAS unit, though one of these newer cases studied the transition with a sleep metabolic load. Several bonus cases of immediate interest to Orion Program staff were also slotted into the tight testing timeline.

The criteria for a test case to be considered complete was GAC1 chamber conditions varying nondirectionally by less than $0.01 \mathrm{kPa}$ partial pressure $\mathrm{CO}_{2}(0.01 \%$ concentration) and $0.28^{\circ} \mathrm{C}\left(0.5^{\circ} \mathrm{F}\right)$ dew point during a period of at least one full cabin air exchange (time $=$ cabin volume $\div$ combined air flow rate through all CAMRASes) or six half-cycles, whichever was longer.

In all the data presented in the following sections, the GAC1 chilled mirror dew point reading was used as the chamber condition and inlet conditions for both CAMRASes for table data, plots, and efficiency calculations. The aluminum oxide sensor moisture readings and GAC3 outlet $\mathrm{CO}_{2}$ analyzers were used for removal efficiency calculations. Efficiency was calculated as an instantaneous value: (inlet - outlet) I inlet. The instantaneous efficiency values were then averaged over six CAMRAS half-cycles for reporting in the following sections. Conversions between dew point and partial pressure of water vapor were calculated using Buck's approximation equations of $1981^{4}$.

\section{TEST RESULTS}

Test results presented from the first two phases in ICES paper 2007-01-3156 were preliminary. Some of the data from that paper has been repeated here in finalized form, but for the complete set of finalized data, consult the CAMRAS Phase 1/2/3 Final Test Report ${ }^{2}$.

VENDOR COMPARISON TESTS - Three Hamilton Sundstrand pre-delivery test cases were recreated as part of the Phase 1 and 2 testing. The setup for the JSC tests was somewhat different than the vendor's rig. Hamilton Sundstrand injected water vapor and carbon dioxide into the CAMRAS inlet line to create specified inlet conditions and evaluated the CAMRAS outlet air flow to determine the removal rates. The JSC team instead varied the HMS input rates to maintain the chamber at the desired atmospheric conditions while the CAMRAS(es) worked. Note that constituent injection rates were not based on metabolic rates in these tests. Another key difference is that the vendor test rig had the CAMRAS exterior exposed to lab temperatures, whereas the JSC rig was exposed to the generally higher chamber temperatures. Temperature mildly affects adsorption and desorption rates, as described in ICES paper 2007-01-3156.

For Phase 3 Part 2, one of those cases was run four more times: once with each of the individual CAMRAS test articles, and twice with both of the test articles working together: once with the spool valves switching at the same time, and once with the spool valves switching position half of a half-cycle offset from one another. All tests were conducted with 6.5-minute half-cycle times. Table 2 compares the results in all four test series. 


\begin{tabular}{|c|c|c|c|c|c|c|c|}
\hline Test Group & 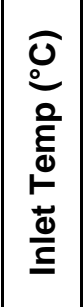 & 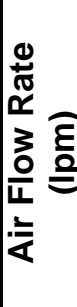 & 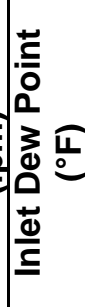 & 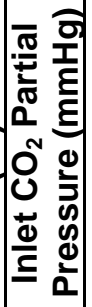 & 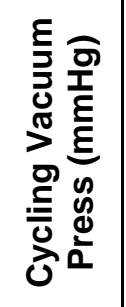 & 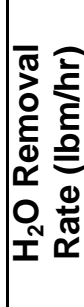 & 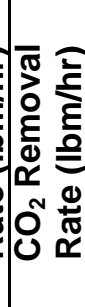 \\
\hline Hamilton & 28.2 & 742 & 41.6 & 2.94 & 1.00 & 0.53 & 0.48 \\
\hline Phase 1 & 27.8 & 702 & 43.0 & $3.3+$ & $2+$ & 0.44 & 0.38 \\
\hline Phase 2 & 26.7 & 702 & 35.8 & 2.93 & 0.38 & 0.47 & 0.42 \\
\hline $\begin{array}{c}\text { Phase } 3 \\
\text { CAMRAS } 1\end{array}$ & 26.9 & 705 & 40.5 & 3.06 & 0.15 & 0.42 & 0.46 \\
\hline $\begin{array}{c}\text { Phase } 3 \\
\text { CAMRAS } 2 \\
\end{array}$ & 26.8 & 705 & 39.6 & 3.09 & 0.15 & 0.39 & 0.39 \\
\hline $\begin{array}{c}\text { Phase } 3 \text { Both } \\
\text { Synced }\end{array}$ & 26.7 & 705 & 39.5 & 2.87 & $\begin{array}{l}0.16 \mathrm{C} 1 \\
0.15 \mathrm{C} 2 \\
\end{array}$ & 0.91 & 0.86 \\
\hline $\begin{array}{l}\text { Phase } 3 \text { Both } \\
\text { Counter-synced }\end{array}$ & 27.1 & 705 & 40.0 & 2.98 & \begin{tabular}{ll|}
$0.16 \mathrm{C} 1$ \\
$0.16 \mathrm{C} 2$
\end{tabular} & 0.94 & 0.89 \\
\hline
\end{tabular}

Table 2 - Comparison of Hamilton Sundstrand Open-Loop and JSC Pseudo-Open-Loop Test Results

In examining the results of Phase 3 it appears that the two units working together actually removed both water vapor and $\mathrm{CO}_{2}$ at a higher rate than the sum of the two individual units' removal. While some of the difference might be attributed to standard uncertainty in the results (instrument error, HMS steam injection inconsistencies, etc.), the more likely explanation is that the reduced volume was not precisely the intended half of the full volume. While the measurements of the chamber and the volume fillers were done with reasonable attention to detail, the chamber is a complex shape, the test rig far more complex than that, and even the volume fillers were not perfectly symmetrical.

The results of the synchronized spool valve position changes versus the counter-synchronized changes confirmed the projection that counter-synchronization is the more efficient operation strategy, though the difference is fairly small. To present the most conservative results, the remainder of Phase 3 testing was run with the spool valves operating in sync and therefore slightly less efficiently.

On the whole, despite small differences attributable to variances in mixing volume, temperature, precise chamber conditions, and vacuum systems, the results of all three test phases can be considered basically comparable to the vendor's pre-delivery test results and to one another.

BASELINE AND MATRIX CASES - Early in Phase 1, "baseline" cases were run that established a norm for comparison with later cases. These were run for both a smaller crew and a larger crew at all three metabolic activity levels, using the "standard" 708 Ipm air flow rate and 6.5-minute spool valve cycle time in a $21^{\circ} \mathrm{C}$ chamber. Because much of the test system had undergone major changes since Phase 1; particularly the chamber volume, metabolic rates, vacuum system, and addition of a test article; the baseline cases were rerun at the beginning of Phase 3 Part 2 testing. In Phase 2, matrix cases were run that investigated the effects of varying air flow rates and spool valve cycle times on the chamber air conditions for the nominal metabolic load only. In Phase 3 Part 2 that matrix was expanded with more nominal metabolic load cases and a number of sleep and exercise cases.

Nominal Metabolic Load - It will be important to identify operational settings that will yield a high enough dew point for the crew's comfort (generally between 30 and $60^{\circ} \mathrm{F}$ ) but below the temperature of the uninsulated coolant loops $\left(45^{\circ} \mathrm{F}\right) . \mathrm{CO}_{2}$ partial pressures must remain low enough to stay well within safe limits for long term exposure (ideally below $3.8 \mathrm{mmHg}$ ). The chamber conditions resulting from the nominal metabolic load baseline and matrix cases are presented in Table 3 . The gray text is from the Phase 2 tests and the black text is from the Phase 3 tests. The two cannot be directly compared due to the differences in chamber volume, metabolic constituent injection rates, and vacuum systems, but the trends are informative. In general, these results show that the longer the cycle time and slower the airflow, the higher the resulting dew point and $\mathrm{CO}_{2}$ partial pressure. $\mathrm{CO}_{2}$ drops rapidly as flow rate is increased and moderately as cycle time is shortened. Similarly, dew points drop moderately as flow rate is increased and a little as cycle time is decreased. The ideal normal operating point with nominal metabolic loads and a larger crew, therefore, most likely lies above a diagonal line from the lower right corner to the upper left corner of Table 3 . The original proposal of $25 \mathrm{cfm}$ air flow and 6.5 minutes cycle time may be just about right for a crew of 6 at a nominal metabolic load. An off-the-cuff extrapolation of the Phase 3 smaller crew baseline results $\left(27.2^{\circ} \mathrm{F}\right.$ dew point, $1.04 \mathrm{mmHg} \mathrm{CO}$ partial pressure), based on the trends in Table 3 , suggests that reducing the blower speed to $15 \mathrm{cfm}$ with the same 6.5 minute cycle time may be appropriate for the nominal metabolic load of a crew of 4 . 


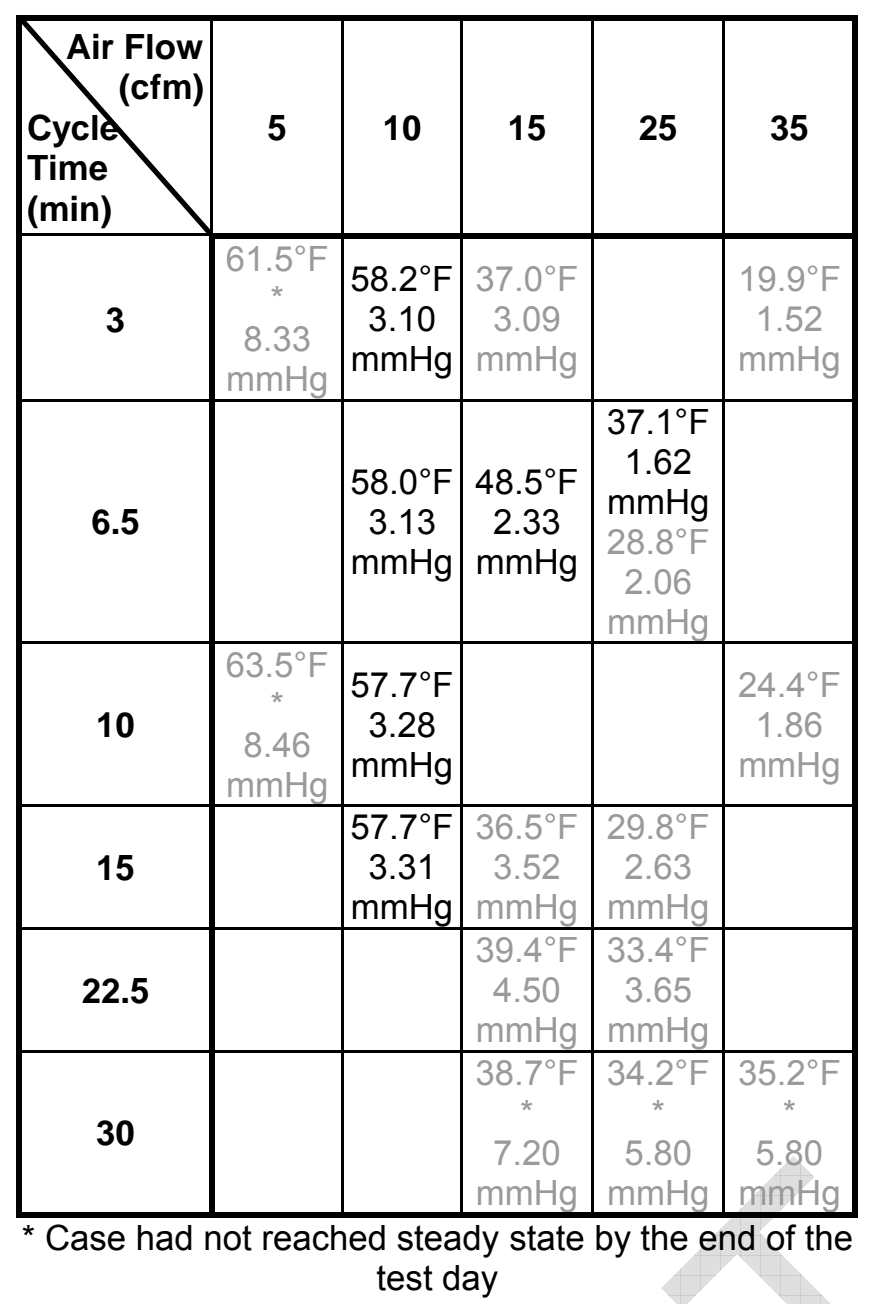

Table 3 - Larger Crew Nominal Load Matrix Test Results: Chamber Dew Points and $\mathrm{CO}_{2}$ Partial Pressures

The Phase 3 Part 2 nominal metabolic load baseline cases were also run with each CAMRAS individually and with both working together. As suggested by the results of the vendor comparison tests, this confirmed that CAMRAS 1, with its dual-end desorption, is typically somewhat more efficient than CAMRAS 2 with its singleend desorption.

Sleep Metabolic Load - Results of baseline cases showed that the standard CAMRAS operating conditions overdried the cabin during sleep periods. The results of the Phase 3 Part 2 smaller crew baseline case, along with the results of all the matrix sleep cases, are depicted in a matrix format in Table 4. Trends across the sleep matrix are similar to the trends seen on the nominal matrix in the previous section, though the comparatively low dew points across the table suggest that the ideal operating conditions here are on the opposite side of that diagonal line from the lower right corner to the upper left. The $\mathrm{CO}_{2}$ partial pressures are low enough across the board to support that approach as well. Based on this data, it seems likely that $10 \mathrm{cfm}$ air flow and 30 minutes cycle time should maintain sufficient moisture in the cabin air for the crew's comfort without threatening the $45^{\circ} \mathrm{F}$ cooling system-driven upper dew point limit. An off-the-cuff extrapolation of the Phase 3 baseline results for a larger crew $\left(23.5^{\circ} \mathrm{F}\right.$ dew point, $0.97 \mathrm{mmHg} \mathrm{CO}_{2}$ partial pressure), based on the trends in Table 4, suggests that increasing the blower speed to $15 \mathrm{cfm}$ with the same 30 minute cycle time may be appropriate for the larger crew's sleep metabolic load.

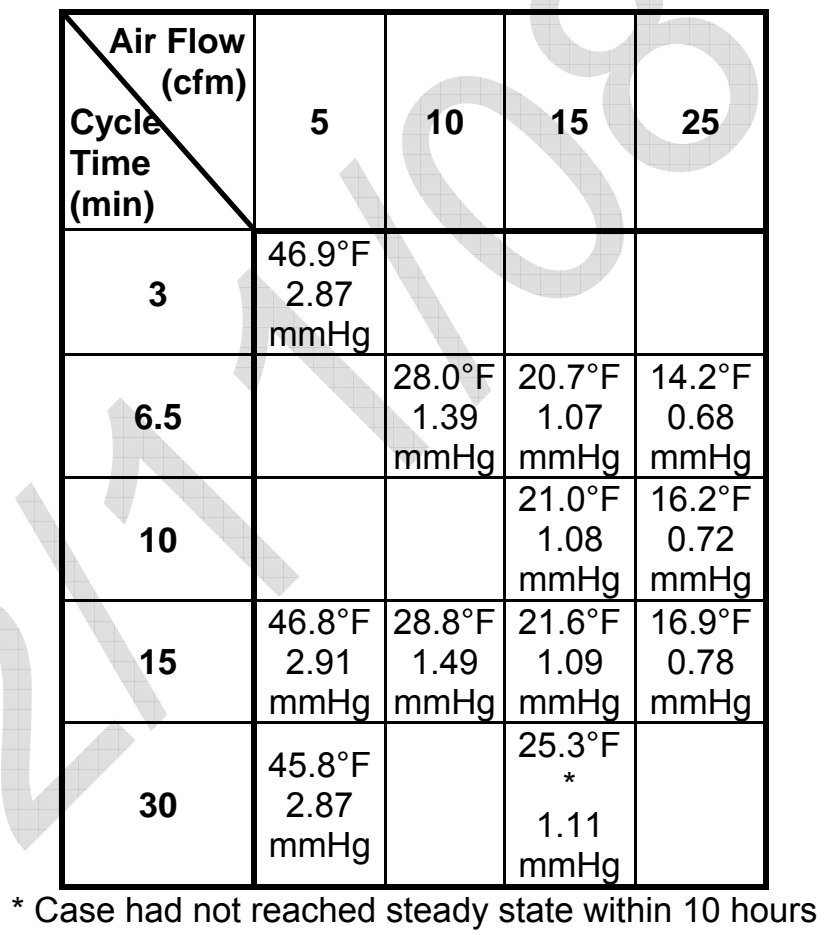

Table 4 - Smaller Crew Sleep Matrix Test Results: Chamber Dew Points and $\mathrm{CO}_{2}$ Partial Pressures

Exercise Metabolic Load - Exercise metabolic loads, unlike normal and sleep loads, are not steady. For CAMRAS testing, each of four simulated crew members exercised in succession for 30 minutes each, with a 15minute break between. Water vapor loads are higher after the first exerciser's active period because the first exerciser is still sweating and cooling down for an hour. Including cool-down periods, an exercise scenario of this type lasts nearly four hours. Because of the nature of the HMS design, the smooth curves of an exercise water vapor load could not be precisely replicated and were instead approximated by step changes in input rate setpoints every 7.5 minutes. The total exercise HMS injection rate magnitudes changed for Phase 3 based on the changes to the nominal metabolic load, but the constituent injection profiles were the same basic shape as previously presented in ICES paper 2007-01-3156.

It was discovered partway through Phase 3 Part 2 testing that liquid water had been dripping out of the HMS outlet and puddling on the chamber floor instead of being injected into the atmosphere wholly as water vapor. As a result, the peak chamber dew points read in 
all the exercise cases are probably somewhat lower than they should be, and all of the curves probably are slightly broader and flatter due to later evaporation of the water introduced as liquid. Several of the exercise cases were also run during a period when a steam pressure relief valve in the HMS was leaking slowly. The water from both sources was captured and quantified as best possible, though correction of the test results for those water inconsistencies was not considered reasonably feasible. Non-exercise cases are considered unlikely to have been affected by the dripping water issue due to far lower water injection rates and, consequentially, easier maintenance of steam-phase water vapor all the way into the chamber.

The results of the baseline and three matrix exercise load test cases in Phase 3 Part 2 are presented in Table 5. A plot of the $\mathrm{CO}_{2}$ and $\mathrm{H}_{2} \mathrm{O}$ injection rates and resulting chamber partial pressures in the baseline case is shown in Figure 6. This plot is typical of all exercise scenario plot shapes.

\begin{tabular}{|l|c|c|c|c|}
\hline $\begin{array}{l}\text { Spool Valve Cycle } \\
\text { Period (min) }\end{array}$ & 6.5 & 3 & 3 & 6.5 \\
\hline Blower Flow Rate (cfm) & 25 & 25 & 35 & 35 \\
\hline Starting Dew Point ( $\left.{ }^{\circ} \mathrm{F}\right)$ & 29.7 & 26.7 & 22.5 & 24.0 \\
\hline $\begin{array}{l}\text { First Peak Dew Point } \\
\left({ }^{\circ} \mathrm{F}\right)\end{array}$ & 53.0 & 46.6 & 46.5 & 49.2 \\
\hline $\begin{array}{l}\text { Highest Peak Dew Point } \\
\left({ }^{\circ} \mathrm{F}\right)\end{array}$ & 58.0 & 51.0 & 49.3 & 54.2 \\
\hline $\begin{array}{l}\text { Liquid Water Collected } \\
\text { (ml) }\end{array}$ & $*$ & 402 & $\begin{array}{c}217- \\
301\end{array}$ & $*$ \\
\hline $\begin{array}{l}\text { Highest Peak CO} \mathbf{~}_{2} \text { Partial } \\
\text { Pressure (mmHg) }\end{array}$ & 2.99 & 2.68 & 2.36 & 2.37 \\
\hline
\end{tabular}

${ }^{*}$ Dripping water had not yet been discovered.

${ }^{\dagger}$ The HMS steam pressure relief collection bag held 84 $\mathrm{ml}$ from this case plus another prior case the same day.

Table 5 - Smaller Crew Exercise Load Matrix Test Results

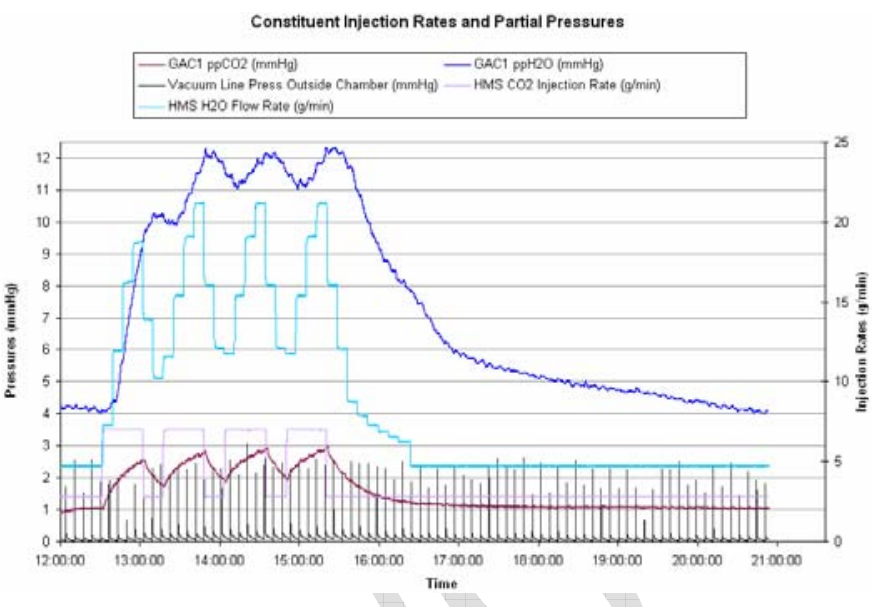

Figure 6 - Baseline Exercise Scenario Metabolic Constituent Input Rates and Resulting Chamber Conditions as Controlled by Two CAMRASes

It was observed over the course of all the exercise runs that the first peak dew point is more heavily influenced by the dew point preceding the exercise profile initiation than are the later peaks. While the test operators endeavored to start each case at approximately the same dew point (equal to the steady state conditions of the 4-person nominal baseline case), there were small variations each time.

In the end, the results of the $35 \mathrm{cfm}$ air flow and 3 minute cycle time case are encouraging, as the peak dew point is only slightly above the allowed $45^{\circ} \mathrm{F}$. Even if that much air flow is not available due to limitations in vehicle blower design, reducing the spool valve cycle time to 3 minutes with $25 \mathrm{cfm}$ of air flow would still provide a considerably lower peak dew point than the standard 6.5 minute cycle time.

BONUS EXERCISE CASES - Several options may be available to bridge the small gap between the best exercise matrix case results and the allowed maximum cabin dew point:

a different real-world crew mix might have lower metabolic output rates.

the crew could exercise at a slightly easier rate to reduce their metabolic output.

separating the exercise periods by more than 15 minutes would allow the dew point to drop further between crew members and reduce the overlap accumulation.

preconditioning the cabin to a lower dew point before exercising begins could slightly reduce the overall $\mathrm{CO} 2$ and water vapor levels.

conditioning the cabin to a lower temperature before and during the exercise period could cause the crew to sweat less and could allow the CAMRAS to run more efficiently.

running the third CAMRAS unit could reduce the overall moisture and $\mathrm{CO}_{2}$ levels to a greater degree. 
Although it has not yet been determined that Orion crews should exercise less strenuously or with more separation between the crew members' sessions, a preliminary decision has been made to allow temporary excursions above and below the prescribed nominal moisture levels in the cabin, as long as they are not of excessive duration, and as long as the long-term average is within the limits. This is another concession to avoid the undesirable alternative of increasing the size and weight of the CAMRAS units. If water were to condense on any cabin equipment during the brief high humidity periods, it would be most likely to do so in the cabin air heat exchanger, and it should dry off again in short order as soon as the CAMRASes reduce the cabin dew point back below the coolant loop temperature.

Some of these options were of acute interest to Orion Program engineers while the Phase 3 Part 2 tests were in progress. The test managers permitted a few extra cases to be slotted into the test series to get immediate feedback on the real-world practicality of some of those options as alternatives to increasing the size and weight of the CAMRAS bed. Two exercise cases were added to the series as a result of that request.

Three CAMRASes at $37 \mathrm{cfm}$ - Because Orion will have three CAMRAS units (nominally planned as two operational and one backup), it was suggested that the third CAMRAS could be turned on during the exercise period to help handle the heavy moisture load. To see maximum effect, all three units in this first bonus test case were also to be run with the highest blower speed deemed practically feasible for Orion and the current size CAMRAS units, $37 \mathrm{cfm}$. The cycle time was requested to be the standard 6.5 minutes. Because the JSC team only had two CAMRAS units in the test rig, the effects of the third unit had to be simulated, just as the effects of a second unit had been repeatedly simulated in all three test phases. The metabolic loads for the exercise scenario were scaled to $2 / 3$, as was the chamber volume, so that each of the test articles would be scrubbing $1 / 3$ of the metabolic load and $1 / 3$ of the total Orion volume. The altered test volume was $381.9 \mathrm{ft}^{3}$.

As part of the standard setup for exercise cases, the chamber was configured to baseline 4-person nominal conditions and the CAMRAS units were allowed to run for a period with a nominal metabolic load before the exercise metabolic load profile was started. However, because this test was effectively running three CAMRAS units instead of the usual two, the chamber dew point and $\mathrm{CO}_{2}$ concentration dropped rapidly from the baseline conditions, so the balancing period was cut short. Consequently, this test inadvertently tested another of the potential gap-bridging options discussed above, preconditioning of the cabin. However, that likely only affected the initial peak dew point with any significance. Of far greater import here is the highest peak dew point achieved, just barely over the allowed $45^{\circ} \mathrm{F}$ maximum. The results of this test are detailed in Table 6.

\begin{tabular}{|c|c|}
\hline Simulated Number of CAMRASes & 3 \\
\hline Spool Valve Cycle Period (min) & 6.5 \\
\hline Blower Flow Rate (cfm) & 37 \\
\hline Starting Dew Point $\left({ }^{\circ} \mathrm{F}\right)$ & 16.1 \\
\hline First Peak Dew Point ( $\left.{ }^{\circ} \mathrm{F}\right)$ & 39.8 \\
\hline Highest Peak Dew Point $\left({ }^{\circ} \mathrm{F}\right)$ & 45.4 \\
\hline Liquid Water Collected (ml) & 62 \\
\hline Highest Peak $\mathrm{CO}_{2}$ Partial Pressure $(\mathrm{mmHg})$ & 1.45 \\
\hline
\end{tabular}

This test provided strong evidence that the size of the CAMRAS unit did not need to be increased just to handle the metabolic load in an exercise case. Although the vehicle blowers may not be able to push $37 \mathrm{cfm}$ through each of the CAMRAS units, running at $25 \mathrm{cfm}$ through all three units with the shorter 3 minute cycle time should have similar and possibly better results, based on the matrix test data. Preconditioning the chamber dew point just before exercise, performed as an additional measure to running three units, is highly unlikely to cause any harm to crew or equipment, and will probably help slightly reduce the peak dew points.

One Exerciser Only - In order to better understand the effects that spacing the crew members' exercise sessions further apart, an additional test was requested in which only the first exerciser would be tested with otherwise standard baseline operations, and the chamber then allowed to return to nominal steady state conditions. Data was captured on the peaks (Table 7) and chamber atmosphere recovery rates.

\begin{tabular}{|l|c|}
\hline Spool Valve Cycle Period (min) & 6.5 \\
\hline Blower Flow Rate (cfm) & 25 \\
\hline Starting Dew Point ( $\left.{ }^{\circ} \mathrm{F}\right)$ & 25.9 \\
\hline First Peak Dew Point ( $\left.{ }^{\circ} \mathrm{F}\right)$ & 48.8 \\
\hline Liquid Water Collected (ml) & 7 \\
\hline First Peak $\mathrm{CO}_{2}$ Partial Pressure (mmHg) & 2.32 \\
\hline
\end{tabular}

Table 7 - Smaller Crew Exercise Load Bonus SingleExerciser Test Results

The main item of interest in this case was the time it took for the chamber to return to normal steady conditions after the end of the exercise period: 100 minutes after the crewperson stopped exercising (40 minutes after the end of the exercise profile, which includes a 60 minute water production cooldown). A plot of the $\mathrm{CO}_{2}$ and $\mathrm{H}_{2} \mathrm{O}$ injection rates and resulting chamber partial pressures in this case is shown in Figure 7 . These results confirm that if the crew's exercise periods were spread out further the dew point peaks could be better controlled, and the overall time spent at high dew points could be minimized. If 100 minutes were allowed between each exercise period instead of 15 minutes, all four crew 
members could still complete their exercise within a 7 hour period and the cabin would spend only a few minutes at a high dew point every couple of hours.

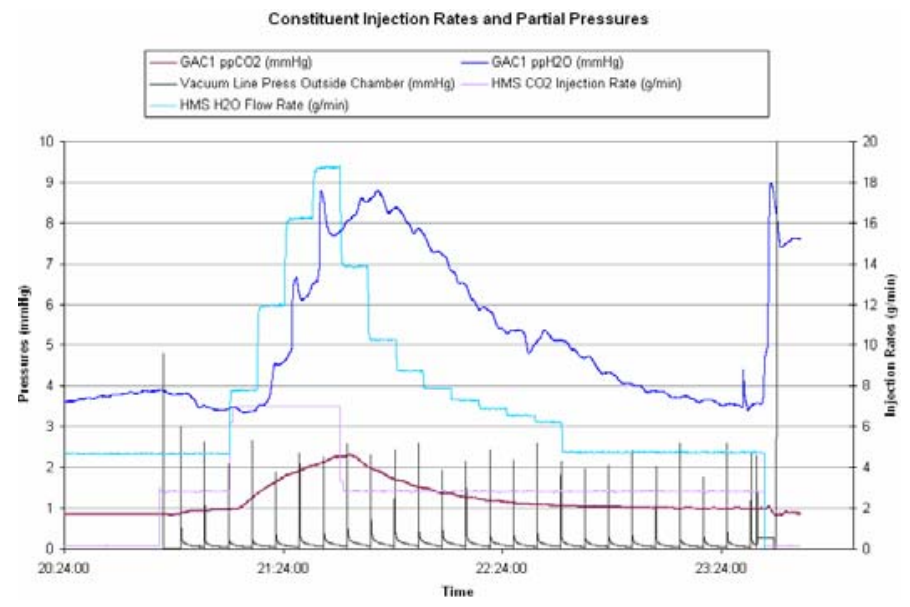

Figure 7 - Single Exercise Scenario Metabolic Constituent Input Rates and Resulting Chamber Conditions as Controlled by Two CAMRASes

FAILURE SCENARIOS - In Phase 3 Part 2 two simulated failure scenarios were run principally to examine the transition period in switching from two CAMRASes to one. The test cases were intended to look at CAMRAS 2 (the single-end desorption unit) because Phase 1 tests had examined CAMRAS 1. One case studied a failure transition from two standardcondition operating units to one with the larger crew at a nominal activity level, and added a simulated deorbit condition at the end of the case, when the vacuum port would be closed, to determine the length of time a single single-end desorb unit could maintain a safe atmosphere should a landing be required with only one CAMRAS in operation. The other case studied the effects of the same failure happening while the larger crew was asleep. It did not include the deorbit portion, as it is highly unlikely that the crew would be asleep during a landing sequence.

During the course of the Phase 3 testing, as part of the question of CAMRAS sizing for the highest demand situations (exercise and failures), two additional cases were added. One was a repeat of the Phase 1 case simulating a single CAMRAS (CAMRAS 1 ) with a $25 \mathrm{cfm}$ blower supporting a larger crew. The new test was intended to illustrate the differences due to the changed chamber volume, metabolic rates, and vacuum system. The second added case was just like the first, but with the blower running at $37 \mathrm{cfm}$, again much like one of the Phase 1 cases. Table 8 details the test results.

\begin{tabular}{|l|c|c|c|c|}
\hline $\begin{array}{l}\text { Spool Valve Cycle } \\
\text { Period (min) }\end{array}$ & 6.5 & 6.5 & 6.5 & 6.5 \\
\hline Blower Flow Rate (cfm) & 25 & 25 & 37 & 25 \\
\hline Operating CAMRAS & 1 & 2 & 1 & 2 \\
\hline Metabolic Load Type & nom & nom & nom & $\begin{array}{c}\text { slee } \\
\text { p }\end{array}$ \\
\hline Dew Point ( $\left.{ }^{\circ} \mathrm{F}\right)$ & 52.9 & 54.2 & 47.7 & 38.0 \\
\hline $\begin{array}{l}\mathrm{CO}_{2} \text { Partial Pressure } \\
\text { (mmHg) }\end{array}$ & 3.39 & 4.72 & 2.97 & 2.50 \\
\hline $\begin{array}{l}\text { Cycling Vacuum } \\
\text { Pressure (mmHg) }\end{array}$ & 0.30 & 0.31 & 0.23 & 0.20 \\
\hline
\end{tabular}

Table 8 - Failure Scenario Test Results

In these failure scenarios it was demonstrated that the CAMRAS can readily maintain the cabin atmosphere at safe conditions for extended periods of time. The dew point may not remain low enough to preclude condensation on the cooling loops inside the Orion cabin unless the crew stays asleep. Similarly, the $\mathrm{CO}_{2}$ partial pressure may well be higher than the nominal preferred level in some situations, but it is still well within normal spacecraft allowable maximums in all cases.

In the Phase 3 sleep load transition case, the chamber conditions took about 4 hours to move from the baseline steady conditions to the new steady conditions. The Phase 3 nominal load transition case (Figure 8) also took about 4 hours for the dew point to move from the baseline steady level to the new steady dew point. In this same case, the carbon dioxide concentration took about 5 hours to move from the baseline steady level to the new steady level. In both cases, $75 \%$ of the water partial pressure change occurred within the first hour after the failure, while $75 \%$ of the $\mathrm{CO}_{2}$ partial pressure change took about 1.5 hours in the sleep case and nearly 2 hours in the normal metabolic load case. When the nominal load case had been deemed dynamically steady state after the "failure", the vacuum to the operational CAMRAS (CAMRAS 2) was shut off, but the blower was kept on at the same $25 \mathrm{cfm}$ and the spool valve kept cycling every 6.5 minutes. From the time the vacuum was shut off, CAMRAS 2 was able to keep the chamber $\mathrm{CO}_{2}$ partial pressure below $7.6 \mathrm{mmHg}$ for 40 minutes, though the dew point rose to about $66^{\circ} \mathrm{F}$ in that period. 


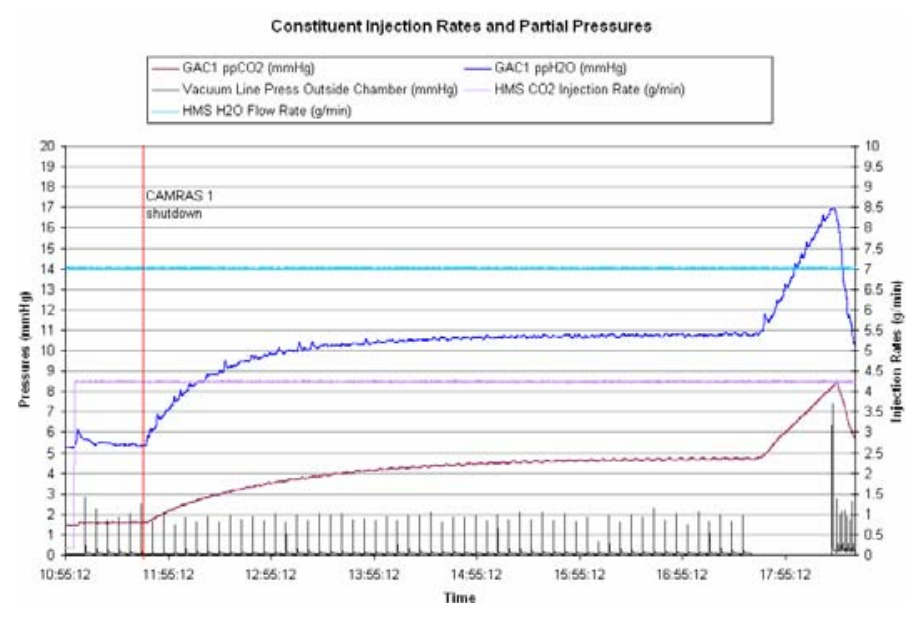

Figure 8 - Nominal Failure Transition and Deorbit Case Metabolic Constituent Input Rates and Resulting Chamber Conditions as Controlled by Two CAMRASes

VACUUM PRESSURE EFFECTS - In Phase 3 Part 2 two degraded vacuum cases were run with the new metabolic rates and vacuum pressures to supplement the information gained from tests performed in Phase 1. Data from the baseline cases and the deliberately degraded vacuum cases from both Phase 1 and Phase 3 were combined in Figure 9 and Figure 10 to illustrate the general magnitude of the CAMRAS efficiency dependence on good vacuum. Exponential trend lines added by Excel illustrate the trends in the data sets. All these cases were conducted with the same flow rates, cycle times, and chamber temperatures (with normal slight variations in temperature).

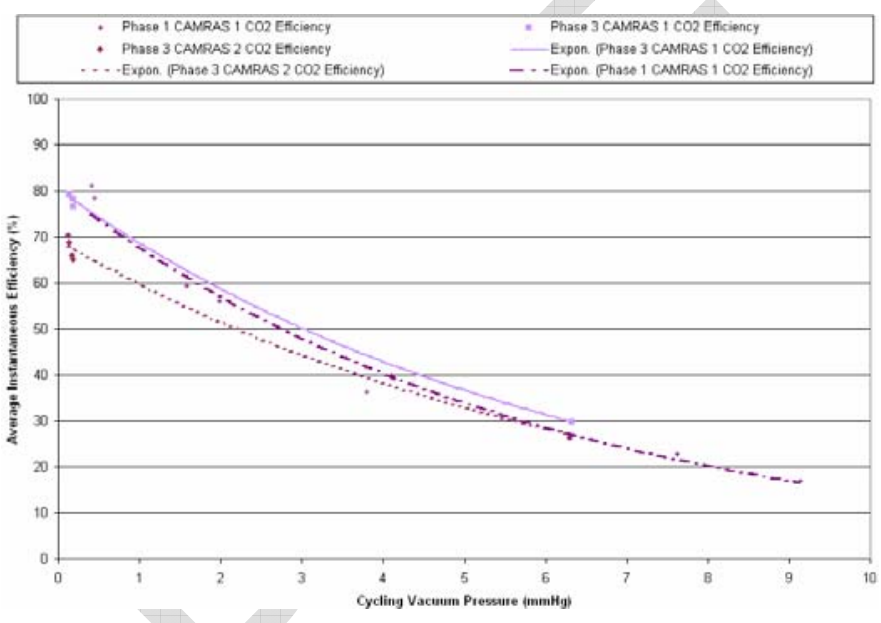

Figure $9-\mathrm{CO}_{2}$ CAMRAS Efficiencies versus Cycling Pressure

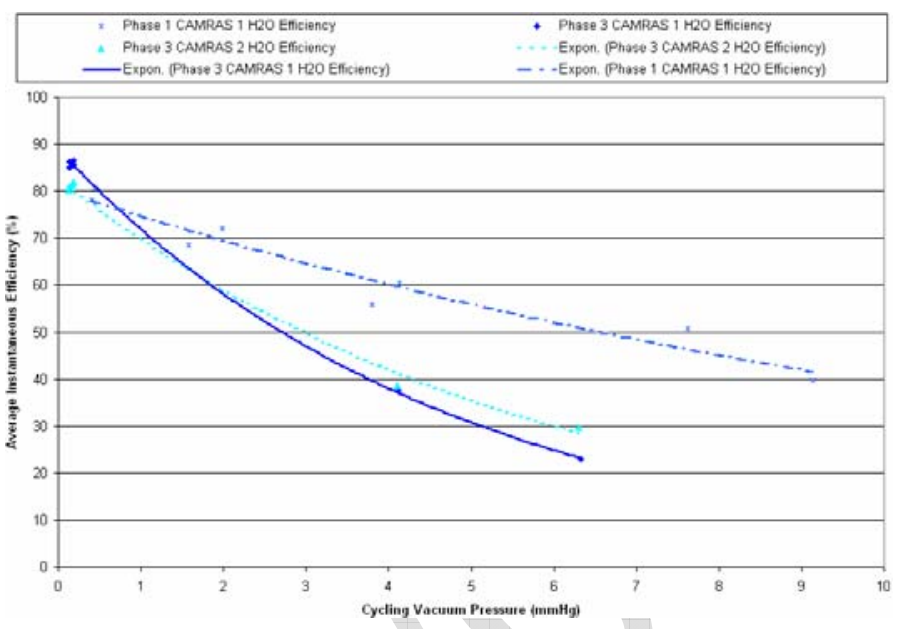

Figure $10-\mathrm{H}_{2} \mathrm{O}$ CAMRAS Efficiencies versus Cycling Pressure

The higher (more efficient) set of points on the Phase 1 water line represent the larger crew metabolic load, but the same consistent separation is not evident on the $\mathrm{CO}_{2}$ points. (Phase 3 did not test smaller crews at degraded vacuum.) This data clearly shows that CAMRAS $\mathrm{CO}_{2}$ removal efficiency falls off rapidly as the vacuum line pressure increases, and the curve seems relatively independent of particular CAMRAS unit configuration, chamber volume, and injection rate. CAMRAS 2 is less sensitive to increasing vacuum pressure than CAMRAS 1 for both constituents, most likely because it is already more limited in desorption rate due to its single-end desorption design, but the difference is small. The water vapor removal curves show a drastic slope change between Phase 1 and Phase 3, but the reason for that is truly unclear. More degraded vacuum cases have already been planned for the next phase of testing, so those tests should shed additional light on this mystery.

GAS PURGE TESTS - The CAMRAS design was modified for the CAMRAS 2 test article. The modified design allows the CAMRAS to be purged with a pressurized supply of dry $\mathrm{CO}_{2}$-free gas in the absence of a suitable vacuum source. The launch pad is the only planned use of this capability, but it allows more flexibility for long launch preparation and hold times than reliance on prescrubbed CAMRASes without any desorption vehicle, as tested in Phase 1 . Two gas options were explored in Phase 3 Part 1 testing: nitrogen $\left(\mathrm{N}_{2}\right)$ and air.

Purge Baselines - The first portion of the gas purge tests examined baseline conditions similar to the vacuum baseline cases, run with $25 \mathrm{cfm}$ of air flow and a 6.5 minute spool valve cycle time. Both purge gases were tested for both smaller and larger crews at nominal metabolic rates. The test details are listed in Table 9. 


\begin{tabular}{|l|c|c|c|c|}
\hline Simulated Crew Size & 4 & 4 & 6 & 6 \\
\hline $\begin{array}{l}\text { Spool Valve Cycle } \\
\text { Period (min) }\end{array}$ & 6.5 & 6.5 & 6.5 & 6.5 \\
\hline Blower Flow Rate (cfm) & 25 & 25 & 25 & 25 \\
\hline $\begin{array}{l}\text { Purge Gas Flow Rate } \\
\text { (cfm) }\end{array}$ & 25 & 25 & 25 & 25 \\
\hline Purge Gas Type & air & $\mathrm{N}_{2}$ & air & $\mathrm{N}_{2}$ \\
\hline Dew Point ('F) & 34.5 & 34.7 & 44.2 & 44.0 \\
\hline $\begin{array}{l}\mathbf{C O}_{2} \text { Partial Pressure } \\
\text { (mmHg) }\end{array}$ & 2.54 & 2.07 & 3.50 & 3.04 \\
\hline
\end{tabular}

Table 9 - Gas Purge Baseline Test Results

After each baseline case had achieved steady state conditions, the purge gas was turned off and the CAMRAS allowed to continue air flow and valve cycling until the chamber $\mathrm{CO}_{2}$ level reached $7.6 \mathrm{mmHg}$, as in the Phase 1 launch scenario cases. This determined how much time the crew would have at safe $\mathrm{CO}_{2}$ levels after purge gas disconnection at liftoff. For the larger crew, the system was able to maintain $\mathrm{CO}_{2}$ below 7.6 $\mathrm{mmHg}$ for roughly 50 minutes, and the smaller crew lasted for 90 minutes.

Figure 11 shows the difference in constituent removal efficiencies for the two different CAMRAS units with both nominal vacuum-driven desorption and the $25 \mathrm{cfm}$ gasdriven desorption. Results are averaged from the Phase 3 baseline results for smaller and larger crews on the individual CAMRAS units. Chamber temperature for the vacuum cases was about $68^{\circ} \mathrm{F}$, and for the gas cases about $75^{\circ} \mathrm{F}$.

Water and $\mathrm{CO2}$ Removal Efficiency: Vacuum versus Purge Gas

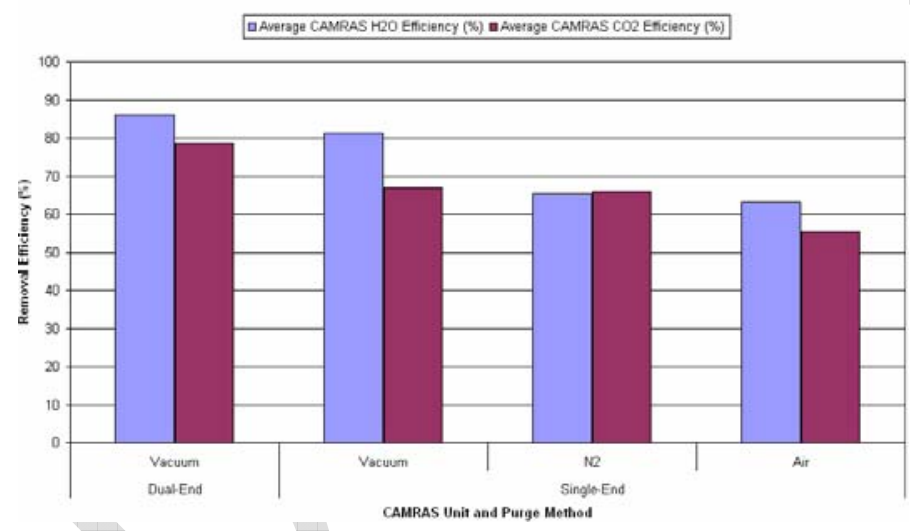

Figure 11 - Efficiency Comparison: Vacuum Purge versus Gas Purge

From this chart it is apparent that the single-end desorption unit performs less efficiently than the dualend unit during vacuum desorption, but the $\mathrm{CO}_{2}$ removal is hurt more significantly than the water vapor removal. When a gas purge is used instead of a vacuum purge on a single-end desorption CAMRAS, water vapor removal is hurt more than $\mathrm{CO}_{2}$ removal. It is also apparent that air is a less effective purge gas than pure nitrogen, particularly for $\mathrm{CO}_{2}$ control. However, air is the preferable purge gas due to an important adverse effect discovered from these baseline tests: $\mathrm{N}_{2}$ purging tends to deplete the atmospheric oxygen $\left(\mathrm{O}_{2}\right)$ too quickly. This is because cabin air lost to ullage during each CAMRAS half-cycle is replaced not with more air at roughly $21 \%$ oxygen concentration, but instead with pure $\mathrm{N}_{2}$. Even without accounting for normal human consumption during the steady state portion of the larger crew $\mathrm{N}_{2}$ purge case run, the cabin oxygen concentration had dropped from $20.8 \%$ to $19.6 \%$ over a period of just under 7 hours. If the crewpeople had concurrently been converting oxygen to $\mathrm{CO}_{2}$ through normal respiration the period for that change would have been greatly shortened. The Occupational Safety and Health Administration considers concentrations below 19.5\% hazardous. Air purge tests did drop the chamber oxygen level slightly, but to a far smaller degree. Because of the rapid oxygen depletion with the nitrogen purge, all of the gas purge matrix tests that followed the baseline runs were conducted using air as the purge gas, and it is highly recommended that dry compressed air be used as the purge gas of choice on the launch pad.

Gas Purge Matrix Cases - A number of vacuum-purged matrix cases were described earlier. A similar strategy was pursued to examine the relationship between purge gas flow rate and spool valve cycle time, and between purge gas flow rate and cabin air flow rate. The cabin air flow rate was kept constant at $15 \mathrm{cfm}$ for all the gas purge matrix tests. That particular rate was chosen as a likely candidate for a good cabin condition control rate based on vacuum desorption matrix tests in Phase 2. In retrospect, a higher cabin air flow rate would have been better simply because gas purge desorption is not as efficient as vacuum desorption. None of these cases with $15 \mathrm{cfm}$ cabin air flow maintained a chamber dew point below the desired $45^{\circ} \mathrm{F}$ threshold, but the performance numbers obtained are still useful for their relative relationships. The test results are presented in a matrix in Table 10.

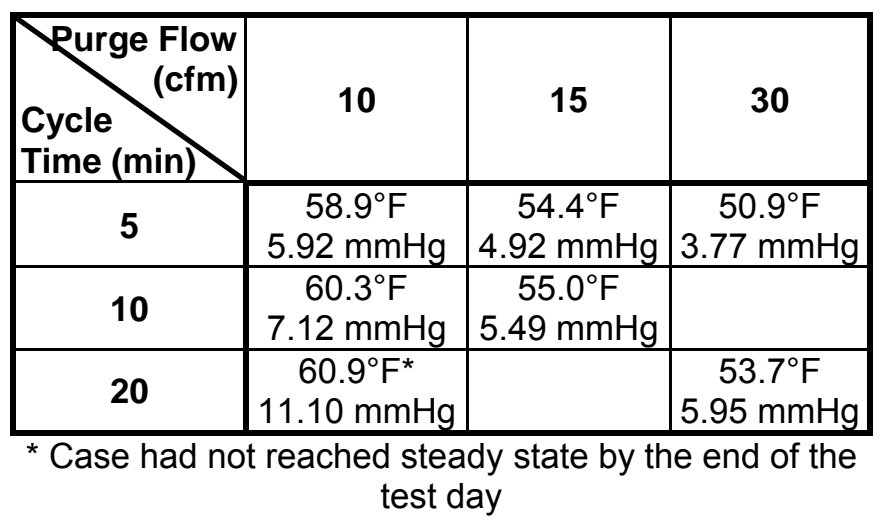

Table 10 - Larger Crew Nominal Gas Purge Matrix Test Results: Chamber Dew Points and $\mathrm{CO}_{2}$ Partial Pressures 
In general these results show that higher purge gas flow rates and cycle frequencies provided the best results, similar to how lower vacuum pressures and short cycle times typically provided the best results in vacuumpurged tests. Purge gas flow slower than the cabin air flow gave very poor performance, and for the 20 minute cycle time with $10 \mathrm{cfm}$ flow, the $\mathrm{CO}_{2}$ levels were unacceptably high and still rising when the test had to be shut down for the day.

\section{RECOMMENDATIONS AND FUTURE TESTS}

Most of the Phase 1 testing and all subsequent baseline testing was done with a standard air flow rate of $25 \mathrm{cfm}$ per unit and a spool valve cycle time of 6.5 minutes. Although that operational combination might be appropriate for nominal metabolic loads and a larger crew, for smaller crews and for sleep metabolic loads it excessively dries the cabin and consumes more blower power than necessary. A comfortable dew point in the cabin is in the 40 to $60^{\circ} \mathrm{F}$ range, but operational considerations on Orion will most likely limit the practical range of the cabin dew point to 35 to $45^{\circ} \mathrm{F}$ to stay above $25 \%$ relative humidity but still prevent condensation on uninsulated cooling lines. For exercise loads, this baseline operational combination is unlikely to be able to maintain the dew point below the $45^{\circ} \mathrm{F}$ Orion target. Other options must be considered to help keep the dew point peaks down.

Phase 2 and Phase 3 Part 2 testing investigated a range of other flow rates and cycle times with the three different metabolic load levels. From these tests it was learned that $10 \mathrm{cfm}$ is probably the most appropriate blower speed for sleep cases, with a very slow 30minute cycle time probably appropriate for a smaller crew to maintain appropriate cabin humidity levels within the comfort zone without losing control of the $\mathrm{CO}_{2}$. Alternately, a single CAMRAS unit running at baseline operational conditions could be used during sleep periods, although that might compromise the system fault tolerance.

To control the moisture peaks during an exercise load, the solution must be more creative than simply a change to flow rate and/or cycle time. While faster air flow rates up to $35 \mathrm{cfm}$ and shorter cycle times down to 3 minutes did help significantly, the faster flow rate may not be a practical implementation for the vehicle. Several other mix-and-match methods also proved promising: preconditioning the atmosphere to start the exercise period at a lower-than-normal dew point, running all three CAMRAS units during the exercise period, and separating the individual crew members' exercise periods by more than 15 minutes. Several other potential assisting factors for exercise periods were identified but not yet explicitly tested: reducing the chamber temperature during the exercise period, reducing the intensity of the workouts, and having a crew made up of people other than only the statistical 82-kg male. During the course of the Phase 3 testing the Orion Program Engineers also agreed that temporary excursions above the target dew point may be allowable, as the coldest location in the vehicle is likely to be the cabin air heat exchanger. While not designed as a condensing heat exchanger, it could withstand occasional wetting, and it would quickly dry again as the CAMRAS caught up with the moisture work load. The possibility of requiring crew members to wear a liquid cooling garment during exercise periods was discussed as a means of controlling water vapor from evaporated sweat, but further investigation suggested that it would not have a significant effect.

Phase 3 Part 1 testing investigated desorption via pressurized purge gas flow for CAMRAS atmosphere control while the Orion vehicle is on the launch pad. While nitrogen was slightly more effective than air as a purge gas, it depleted the cabin oxygen too quickly. At least $25 \mathrm{cfm}$ of both cabin air and purge air will be required to keep both moisture and $\mathrm{CO}_{2}$ levels down.

In general, it was observed that CAMRAS $\mathrm{CO}_{2}$ and $\mathrm{H}_{2} \mathrm{O}$ removal operations are strongly affected by vacuum pressure (lower is better) and air flow rate (higher is better), and affected to a lesser extent by cabin temperature (there is a "sweet spot" around $65-72^{\circ} \mathrm{F}$, with efficiency dropping off as temperature rises, and less so as it falls) and spool valve cycle time (faster is better, more than about 20 minutes compromises $\mathrm{CO}_{2}$ adsorption). To maintain an environment humans will be comfortable in, however, better efficiency and better removal rates are not necessarily better. It is impossible to have too little $\mathrm{CO}_{2}$ in the cabin atmosphere, but the moisture level and cabin temperature must be balanced between peak efficiency, vehicle cooling system design limitations, and peak comfort. The degraded vacuum testing clearly identified the need for good vacuum to enable effective desorption. This suggests that the Orion vacuum line(s) for CAMRAS should be as short and large as possible to allow desorbed gases to be quickly pulled away from the unit and into space with minimal pressure buildup. Simulated failure scenarios in Phases 1 and 3 proved that a single CAMRAS, of either dual or single-end desorb design, can keep a nonexercising crew reasonably comfortable and safe indefinitely, provided the available vacuum pressure is low enough.

Future test plans include:

Real humans in a sealed test chamber, on emergency breathing masks connected to the cabin air loop, and eventually sealed in pressure suits connected to the cabin air loop via umbilicals.

Increased atmospheric oxygen concentrations and any resulting effects on CAMRAS operation.

Investigation of another new CAMRAS design with both spool valve and canister modifications. 
Study of the system performance at reduced cabin pressure and at suit loop pressures.

There is also considerable interest in the ability of the CAMRAS to handle and/or remove trace and gross contaminants. Hamilton Sundstrand has done some testing on subscale units and JSC will do more, but as much of the nondestructive testing as possible will be done on full-scale units. All future tests will rely more heavily on probe-type moisture sensors and replumbed sample racks to avoid the sampling issues seen in Phases 1, 2, and 3.

\section{CONCLUSION}

From August 2006 to August 2007, the performance of a compact and low-power amine-based system for regenerable carbon dioxide and water vapor removal was tested in a realistic simulation of a spacecraft environment. It was proven that the CAMRAS is adequately sized to maintain a safe crew environment. It can easily control $\mathrm{CO}_{2}$ and humidity levels for normal metabolic loads and met requirements even in multiplefailure scenarios. Early projections of operational blower speeds and valve cycle times could be scaled back to provide further power and ullage air savings, because maximum efficiency may not always be required. Cabin temperature variations have relatively little effect on the performance of the unit, but access to a good vacuum source is very important for good operation. Further testing will incorporate improvements to the test rig, particularly in the areas of dew point sensing and metabolic water vapor generation. Planned future testing will refine operational recommendations and investigate system effects on very small volumes such as breathing masks and pressure suits and the effects of modified pressure and atmospheric constituents on the system. All of this past and future data should prove useful in implementing the CAMRAS within the Orion spacecraft, and has already started driving decisions about the implementation of the Orion environmental control and life support systems.

\section{ACKNOWLEDGMENTS}

The author would like to acknowledge Tim Nalette and Bill Papale of Hamilton Sundstrand for providing the test article and preliminary test data as well as technical support during the JSC tests and analysis insights. JSC Test Facility Engineers Matt Blackmer, Jason Pond, Kent Fry, Jeremiah Nassif, and Jeff Hansen designed and directed the facility modifications. The entire JSC Exploration Life Support Air Revitalization team (Fred Smith, Jeff Sweterlitsch, Melissa Campbell, Sao-Dung Lu, and Su Curley, plus John Graf and Kevin Lange) was instrumental in helping design the test points. Fred Smith, Melissa Campbell, Su Curley, and Sao-Dung Lu also assisted by performing some of the test cases, and Jeff Sweterlitsch provided assistance with data analysis. This paper would not have been possible without all their help.

\section{REFERENCES}

1. Lin, A., et al. "Testing of an Amine-Based PressureSwing System for Carbon Dioxide and Humidity Control", 2007-01-3156, Society of Automotive Engineers, Warrendale, PA, 2007.

2. Lin, A. " $\mathrm{CO}_{2}$ And Moisture Removal Amine Swingbed (CAMRAS) Phase 1/2/3 Final Test Report", JSC-xxxxx, NASA Johnson Space Center, Houston, Texas, 2008.

3. NASA, "Constellation Program Human-Systems Integration Requirements", CxP 70024, Rev. X, Appendix E, 2007.

4. Alduchov, O. and R. Eskridge, "Improved Magnus Form Approximation of Saturation Water Vapor Pressure", Journal of Applied Meteorology, v.35, iss.4, pg.601, American Meteorological Society, Boston, MA, 1996.

\section{CONTACT}

Amy Lin

Mail Code JE77

ESCG/Jacobs Technology

PO Box 58477

Houston, TX 77258-8477

281-244-5121

amy.b.lin@nasa.gov

\section{DEFINITIONS, ACRONYMS, ABBREVIATIONS}

ARTIC: Air Revitalization Technology Integration Chamber

Base Pressure: Vacuum system pressure when the CAMRAS test article is idle

CAMRAS: $\mathrm{CO}_{2}$ And Moisture Removal Amine Swingbed

$\mathrm{CO}_{2}$ : Carbon Dioxide

Cycling Pressure: Asymptotic vacuum system pressure toward the end of each half-cycle when the CAMRAS test article is operating

ELS: Exploration Life Support

GAC: Gas Analyzer Console

$\mathbf{H}_{2} \mathbf{O}$ : Water

HMS: Human Metabolic Simulator

HSIR: Human Systems Integration Requirements

JSC: Johnson Space Center

NASA: National Aeronautics and Space Administration

$\mathbf{N}_{2}$ : Nitrogen

$\mathrm{O}_{2}$ : Oxygen

RCRS: Regenerative $\mathrm{CO}_{2}$ Removal System 